\title{
MULTIPLICAÇÃO IN VITRO DE PORTA-ENXERTOS DO GÊNERO PRUNUS SOB DIFERENTES CONCENTRAÇÕES DE BAP EM DOIS MEIOS DE CULTURA ${ }^{1}$
}

\author{
CARLOS AUGUSTO POSSER SILVEIRA², JOSÉ CARLOS FACHINELLO ${ }^{3}$, GÉRSON RENAN DE LUCES \\ FORTES $^{4}$, IDEMIR CITADIN ${ }^{2}$, ALEXANDRE COUTO RODRIGUES ${ }^{2}$, \\ ALBERTO CENTELLAS QUEZADA², JOÃO BAPTISTA DA SILVA ${ }^{5}$
}

\begin{abstract}
RESUMO - Este trabalho teve como objetivo determinar a melhor concentração de BAP (6-benzilaminopurina) e meio de cultura para a multiplicação in vitro de porta-enxertos de Prunus sp., recentemente introduzidos no Brasil. Os porta-enxertos G x $\mathrm{N}_{22}, \mathrm{GF} 677$, Mr.S 2/5, Marianna e Mirabolano foram testados em dois meios de cultura, meio MS e meio MS $3 / 4$ (reduzido em $25 \%$ dos sais do meio inteiro), combinados com quatro concentrações da citocinina BAP: 0,$1 ; 0,3 ; 0,5$ e 0,7 mg. $\mathrm{L}^{-1}$. Observou-se que os genótipos apresentaram comportamentos diferentes entre si em relação às concentrações de BAP e aos meios. Concluiu-se que, para os porta-enxertos $\mathrm{G} \mathrm{x} \mathrm{N}_{22}$ e Mr.S 2/5, o melhor meio de multiplicação é o MS 3/4 com BAP na concentração de $0,7 \mathrm{mg}^{3} \mathrm{~L}^{-1}$; para o porta-enxerto Marianna, o meio MS com BAP na concentração de $0,7 \mathrm{mg}$. $\mathrm{L}^{-1}$; para o porta-enxerto Mirabolano, o meio MS 3/4 com BAP na concentração de $0,5 \mathrm{mg} . \mathrm{L}^{-1}$, sendo que, para este porta-enxerto, o BAP exerce efeito negativo sobre o tamanho das brotações, independentemente do tipo de meio. Já para o porta-enxerto $\mathrm{Gx} \mathrm{N}_{22}$, este efeito se fez notar apenas no meio MS. O porta-enxerto GF 677 não apresentou bons resultados na propagação in vitro.
\end{abstract}

Termos para indexação: citocinina; pessegueiro; cultura de tecidos

\section{IN VITRO MULTIPLICATION OF PRUNUS ROOTSTOCKS IN DIFFERENT BAP CONCENTRATIONS IN TWO CULTURE MEDIA}

\begin{abstract}
The purpose of this work was to determine the best BAP concentration and culture media for the in vitro multiplication of Prunus rootstocks starting from nodal segments. The rootstocks $\mathrm{Gx} \mathrm{N}_{22}$, GF 677 , Mr.S 2/5, Marianna and Mirabolano were tested in two culture media (MS and MS 3/4) combined with four BAP concentrations $\left(0.1 ; 0.3 ; 0.5\right.$ and 0.7 mg.L. L $\left.^{-1}\right)$. It was observed that the genotypes had different performance as the two media and BAP concentrations are concerned. BAP provided better results in the MS $3 / 4$ for the rootstocks $\mathrm{G} \mathrm{X} \mathrm{N}_{22}$ and Mr.S 2/5. For 'Marianna', the best results were found in the MS at 0.7 mg.L-1 BAP. 'Mirabolano', showed better results in the MS $3 / 4$ at $0.5 \mathrm{mg} . \mathrm{L}^{-1} \mathrm{BAP}$ and in the two tested media, the shoot length decreased with the increase for BAP. The rootstock $\mathrm{Gx} \mathrm{N}_{22}$, had the same effect only in the MS medium. The rootstock GF 677 didn't present good results in micropropagation.
\end{abstract}

Index terms: cytokinin, peach, tissue culture

\section{INTRODUÇÃo}

Na multiplicação in vitro, os fatores concentração de citocinina e tipo de meio usado são extremamente importantes para obter bons resultados. Vários meios básicos têm sido utilizados na multiplicação de plantas, sendo que a maioria se baseia no meio MS (Murashige e Skoog, 1962). Modificações e diluições deste meio têm apresentado bons resultados para diversas espécies. Em 1974, Boxus e Quoirin (1974) deram início ao cultivo in vitro de espécies do gênero Prunus, através da cultura de meristemas. Logo após, Tabachnik e Kester (1977) realizaram os primeiros trabalhos de micropropagação de híbridos de pessegueiro e amendoeira, a partir de gemas apicais. Na Itália, Zuccherelli (1979) deu início à multiplicação in vitro de portaenxertos de pessegueiro. Ainda na Itália, Marino (1982) realizou vários trabalhos visando a desenvolver protocolos de multiplicação in vitro de porta-enxertos híbridos de Prunus. Além do tipo de meio, outro aspecto importante na multiplicação in vitro está relacionado com o tipo de citocinina e sua concentração, sendo ambos determinantes no sucesso da multiplicação in vitro (Grattapaglia e Machado, 1998).

Este trabalho teve como objetivo estabelecer os melhores meios de cultura e concentração de BAP para a multiplicação de porta-enxertos do gênero Prunus.

\footnotetext{
1 (Trabalho 001/2001). Recebido: 08/01/2001. Aceito para publicação: 31/07/2001. Parte da dissertação de mestrado do primeiro autor junto ao Programa de Pós-Graduação em Agronomia, área de concentração Fruticultura de Clima Temperado, FAEM-UFPel/Embrapa Clima Temperado, Pelotas, RS. E-mail: posser@ufpel.tche.br

2 Pós-graduandos em Fruticultura de Clima Temperado, FAEM-UFPel/Embrapa Clima Temperado, Pelotas, RS.

3 Prof. Dr. FAEM/UFPel, Pelotas, RS.

4 Prof. Dr., Pesquisador Embrapa Clima Temperado, Pelotas, RS.

5 Prof. Livre Docente, IFM/UFPel, Pelotas, RS.
} 


\section{MATERIAL E MÉTODOS}

O experimento foi conduzido no Laboratório de Cultura de Tecidos da Embrapa Clima Temperado, Pelotas-RS. Os portaenxertos utilizados foram: $\mathrm{Gx} \mathrm{N}_{22}$, GF 677, Marianna, Mirabolano e Mr.S 2/5. Os explantes (segmentos nodais) originaram-se de subcultivos anteriores do mesmo laboratório. O tamanho do explante variou de acordo com o porta-enxerto, ficando em torno de 5,0 mm e/ou 5 gemas. Foram usados dois meios de cultura, MS e MS 3/4 (reduzido em 25\% dos sais do meio inteiro), combinados com quatro concentrações da citocinina BAP (6benzilaminopurina): 0,1; 0,3; 0,5 e 0,7 mg.L $\mathrm{L}^{-1} \mathrm{~A}$ ambos os meios foram acrescidos 30 g. $\mathrm{L}^{-1}$ de sacarose, 6,5 g.L $\mathrm{L}^{-1}$ de ágar e 100 mg. $\mathrm{L}^{-1}$ de mio-inositol. $\mathrm{O} \mathrm{pH}$ foi ajustado para 5,8 antes da colocação do ágar. Os meios foram distribuídos em frascos de $250 \mathrm{~mL}$ com $8 \mathrm{~cm}$ de diâmetro. Em cada frasco, colocaram-se 30 $\mathrm{mL}$ de meio. Após, foram autoclavados à temperatura de $121^{\circ} \mathrm{C}$, durante 15 minutos. Em cada frasco, foram colocados 5 (cinco) explantes. Após a colocação destes, os frascos foram levados para sala de crescimento, sob condições de luz fluorescente, com intensidade de $20 \mu \mathrm{E} . \mathrm{m}^{-2} \cdot \mathrm{s}^{-1}$, fotoperíodo de 16 horas e temperatura de $25 \pm 2^{\circ} \mathrm{C}$, permanecendo nestas condições por período de 35 dias.

O delineamento experimental foi em blocos casualizados, com 4 (quatro) repetições, sendo cada unidade experimental constituída de um frasco contendo 5 (cinco) segmentos nodais. O delineamento de tratamento foi um fatorial $2 \times 4 \times 5$, sendo os fatores Meio de cultura (MS e MS 3/4), Concentração de BAP $\left(0,1 ; 0,3 ; 0,5\right.$ e $\left.0,7 \mathrm{mg} . \mathrm{L}^{-1}\right)$ e Porta-enxerto $\left(\mathrm{Gx} \mathrm{N}_{22}\right.$, GF 677, Marianna, Mirabolano e Mr.S 2/5).

As variáveis analisadas foram: número de gemas e de brotações (transformadas segundo $\sqrt{x+1}$ e $\sqrt{x+0,5}$, respectivamente), e tamanho das brotações (em mm). A análise estatística dos dados foi feita através da análise da variação e decomposição da variação para os fatores Meio e Porta-enxerto, pela comparação de médias através do teste de Duncan $(\alpha=0,05)$, e Concentração de BAP, pela análise de regressão polinomial. $\mathrm{O}$ nível mínimo de significância adotado em todos os testes foi de $5 \%$. As análises estatísticas foram executadas pelo programa SANEST - Sistema de Análise Estatística para Microcomputadores (Zonta e Machado, 1984).

\section{RESULTADOS E DISCUSSÃO}

$\mathrm{Na}$ Tabela 1, são apresentados os resultados da variável número de gemas. No meio $\mathrm{MS} 3 / 4$, o porta-enxerto $\mathrm{G} \times \mathrm{N}_{22}$ foi superior aos demais, enquanto no MS, o porta-enxerto Mirabolano foi melhor (o porta-enxerto $\mathrm{G}_{\mathrm{x}} \mathrm{N}_{22}$ foi o único que apresentou resposta significativamente superior em relação ao tipo de meio, preferindo aquele menos concentrado). Os meios baseados em formulações básicas diluídas têm possibilitado melhores resultados para a multiplicação das mais diversas espécies (Preece, 1995). Na Figura 1A, observa-se o comportamento do $\mathrm{G} \times \mathrm{N}_{22}$ em função da concentração de BAP nos dois meios testados. No meio $\mathrm{MS} 3 / 4$, o número de gemas aumentou linearmente de acordo com o aumento de BAP, já no meio MS, as melhores respostas foram obtidas na concentração de $0,34 \mathrm{mg} \cdot \mathrm{L}^{-1}$.
Os porta-enxertos responderam diferentemente às concentrações de BAP (Figura 1A-1F). De acordo com Zimmerman (1988), as necessidades das cultivares dentro de uma mesma espécie são diferentes, havendo necessidade de modificação do meio e doses de citocinina. O comportamento do porta-enxerto $\mathrm{Gx} \mathrm{N}_{22}$ indica que meios ricos em sais dificultam a proliferação de gemas. Este fato se agrava ainda mais quando maiores concentrações de BAP forem adicionadas a meios desse tipo. O porta-enxerto Mirabolano não apresentou resposta significativa aos meios e às concentrações de BAP. Apesar disso, as melhores respostas da variável número de gemas foram observadas nas concentrações de 0,5 e $0,7 \mathrm{mg} . \mathrm{L}^{-1}$ de BAP, nos meios MS $3 / 4$ e MS, respectivamente.

Para o tamanho das brotações, observou-se diferença significativa apenas para o porta-enxerto $\mathrm{Gx} \mathrm{N}_{22}$, sendo que as melhores respostas foram obtidas no meio MS $3 / 4$ (Tabela 2 ). No meio MS, este mesmo porta-enxerto apresentou os maiores tamanhos de brotações nas menores concentrações de BAP (Figura 1E). Apesar disso, no meio MS 3/4, o aumento da concentração de BAP não influenciou significativamente o tamanho das brotações (Figura 1E), indicando que, para esse genótipo, meios com sais reduzidos minimizam os efeitos negativos das citocininas. Tabachnik e Kester (1977) observaram que concentrações de 6-BA (6-benziladenina) de até $1,0 \mathrm{mg} . \mathrm{L}^{-1}$ foram melhores para a multiplicação de híbridos de amendoeira e pessegueiro. Por outro lado, concentrações maiores inibiram a elongação das brotações, enquanto a concentração de $0,1 \mathrm{mg}$.L${ }^{1}$ proporcionou o alongamento das brotações. Harada e Murai (1996), em trabalho com o Prunus mume, observaram, no entanto, que o tamanho das brotações não foi influenciado pelas concentrações de benziladenina de até $5 \mu \mathrm{M}$, sendo que a maior proliferação de gemas foi obtida nessa concentração. Segundo Grattapaglia e Machado (1998), muitas vezes, concentrações crescentes de citocininas inibem o alongamento das brotações. Boxus (1986), por sua vez, observou que, além da redução na concentração de BAP no meio de multiplicação, é interessante limitar o número de subcultivos com o objetivo de minimizar os efeitos negativos das citocininas.

Os porta-enxertos Marianna, no meio MS, e Mr.S 2/5 tiveram comportamento semelhante, ou seja, à medida que aumentou a concentração de BAP, aumentou o número de gemas (Figura 1C e 1B, respectivamente). Marino (1982) observou que concentração de BAP de 1,0 mg.L.-1 possibilitou maiores taxas de multiplicação de Prunus, porém o tamanho das brotações foi muito pequeno, dificultando a separação das gemas. Analisando conjuntamente as variáveis número de gemas e tamanho das brotações, para os porta-enxertos $\mathrm{G} \times \mathrm{N}_{22}$, no meio $\mathrm{MS}$, e Mirabolano, os resultados obtidos estão de acordo com Marino (1982). O porta-enxerto Mirabolano apresentou, no meio MS, as melhores respostas para o número de brotações, sendo significativamente superior aos demais (Tabela 3). A resposta do porta-enxerto Mirabolano indica um comportamento linear decrescente em função das concentrações de BAP (Figura 1D). Possivelmente, os teores endógenos de citocinina deste portaenxerto sejam altos, o que, aliado às doses exógenas, contribuiu para o efeito decrescente desta variável. $\mathrm{O}$ efeito negativo do aumento de BAP também se fez notar na variável tamanho das brotações (Figura 1F). Em relação ao porta-enxerto GF 677, apesar de ser micropropagado comercialmente na Europa, apresenta uma 
TABELA 1 - Número médio de gemas de porta-enxertos de Prunus em dois meios de cultura. FAEM/UFPel - Embrapa Clima Temperado, Pelotas-RS, 1999.

\begin{tabular}{|c|c|c|c|c|c|c|}
\hline \multirow{2}{*}{ Porta-enxerto } & \multicolumn{6}{|c|}{ M e ios } \\
\hline & \multicolumn{3}{|c|}{ M S $3 / 4$} & \multicolumn{3}{|c|}{ M S } \\
\hline $\mathrm{G} \quad \mathrm{x} \quad \mathrm{N}_{22}$ & 22,33 & $\mathrm{a}$ & $\mathrm{A}$ & 16,15 & $\mathrm{~b}$ & $\mathrm{~B}$ \\
\hline $\mathrm{M}$ irabo la no & 19,30 & $\mathrm{~b}$ & A & 20,04 & $\mathrm{a}$ & A \\
\hline $\mathrm{M} \mathrm{r.S} 2 / 5$ & 15,67 & $\mathrm{c}$ & $\mathrm{A}$ & 14,56 & $\mathrm{bc}$ & A \\
\hline M arianna & 12,16 & $\mathrm{~d}$ & A & 13,44 & $\mathrm{c}$ & A \\
\hline G F 677 & 10,57 & $\mathrm{~d}$ & A & 9,27 & & $\mathrm{~A}$ \\
\hline
\end{tabular}

Médias seguidas de mesma letra minúscula, nas colunas, e maiúscula, nas linhas, não diferem entre si pelo teste de Duncan $(\alpha=0,05)$.

TABELA 2 - Tamanho médio das brotações (mm) de porta-enxertos de Prunus em dois meios de cultura. FAEM/UFPel - Embrapa Clima Temperado, Pelotas-RS, 1999.

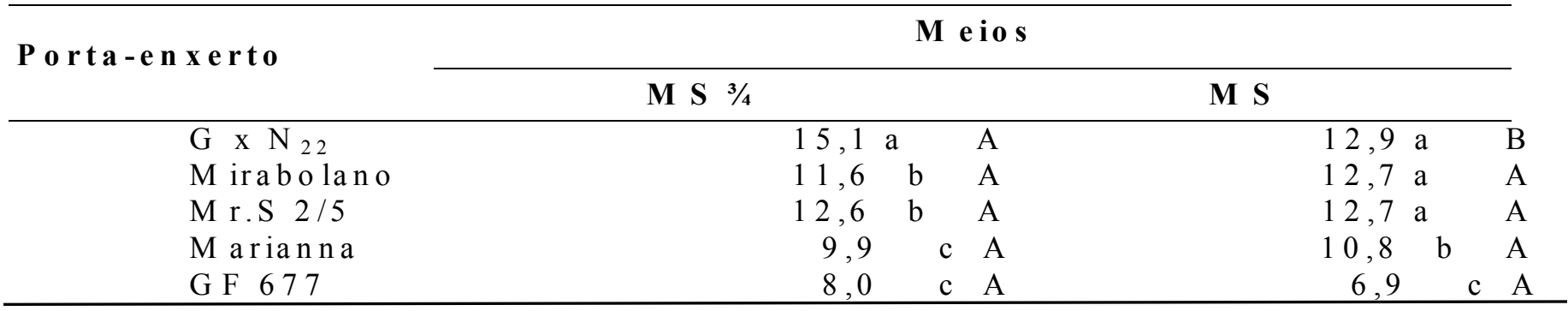

Médias seguidas de mesma letra minúscula, nas colunas, e maiúscula, nas linhas, não diferem entre si pelo teste de Duncan $(\alpha=0,05)$.

TABELA 3 - Número médio de brotações de porta-enxertos de Prunus em dois meios de cultura. FAEM/UFPel - Embrapa Clima Temperado, Pelotas-RS, 1999.

\begin{tabular}{|c|c|c|c|c|c|}
\hline \multirow{2}{*}{ Porta-enxerto } & \multicolumn{5}{|c|}{ M e ios } \\
\hline & \multicolumn{2}{|l|}{ M S $3 / 4$} & \multicolumn{3}{|l|}{$\mathbf{M} \mathbf{S}$} \\
\hline $\mathrm{G} \times \mathrm{N}_{22}$ & 1,63 a b & A & 1,11 & 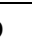 & $\mathrm{B}$ \\
\hline M ir a bo lano & $1,69 \mathrm{a}$ & A & 1,68 a & & A \\
\hline M r.S $2 / 5$ & $1,37 \quad b$ & A & 1,07 & o & B \\
\hline M arianna & $1,53 \mathrm{ab}$ & A & 1,31 & b & A \\
\hline G F 677 & 1,07 & A & 1,06 & $b$ & A \\
\hline
\end{tabular}

Médias seguidas de mesma letra minúscula, nas colunas, e maiúscula, nas linhas, não diferem entre si pelo Teste de Duncan $(\alpha=0,05)$.

taxa de proliferação muito baixa (Dimasi-Theriou \& Economou, 1995). Estes autores, no entanto, conseguiram um elevado número de brotações deste porta-enxerto apenas controlando o tempo de exposição e a concentração de etileno dentro dos frascos. No presente trabalho, este porta-enxerto não apresentou bons resultados, sendo aquele de pior desempenho em todas as variáveis analisadas, além de ser aquele que apresentou maiores percentagens de contaminação in vitro (observações empíricas). É possível que seu desempenho tenha sido influenciado pela presença de bactérias endógenas nos explantes ou mesmo bactérias exógenas presentes no meio de cultura, o que dificultou a absorção dos nutrientes do meio assim como da citocinina. Esse fato certamente mascarou as respostas deste porta-enxerto.

\section{CONCLUSÕES}

1. Para os porta-enxertos $\mathrm{G} \times \mathrm{N}_{22}$ e Mr.S 2/5, o melhor meio de multiplicação foi o MS $3 / 4$ com $0,7 \mathrm{mg} \cdot \mathrm{L}^{-1}$ de BAP.

2. Para o porta-enxerto Marianna, o melhor meio é o MS com 0,7 mg.L-1 de BAP.

3. Para o porta-enxerto Mirabolano, o melhor meio foi o MS $3 / 4$ com $0,5 \mathrm{mg} . \mathrm{L}^{-1}$ de BAP.

4. Para o porta-enxerto Mirabolano, o BAP exerce efeito negativo sobre o tamanho das brotações, independentemente do tipo de meio. Já para o porta-enxerto $\mathrm{G} \times \mathrm{N}_{22}$, este efeito se fez notar apenas no meio MS.

5. O porta-enxerto GF 677 não apresentou bons resultados na propagação in vitro. 

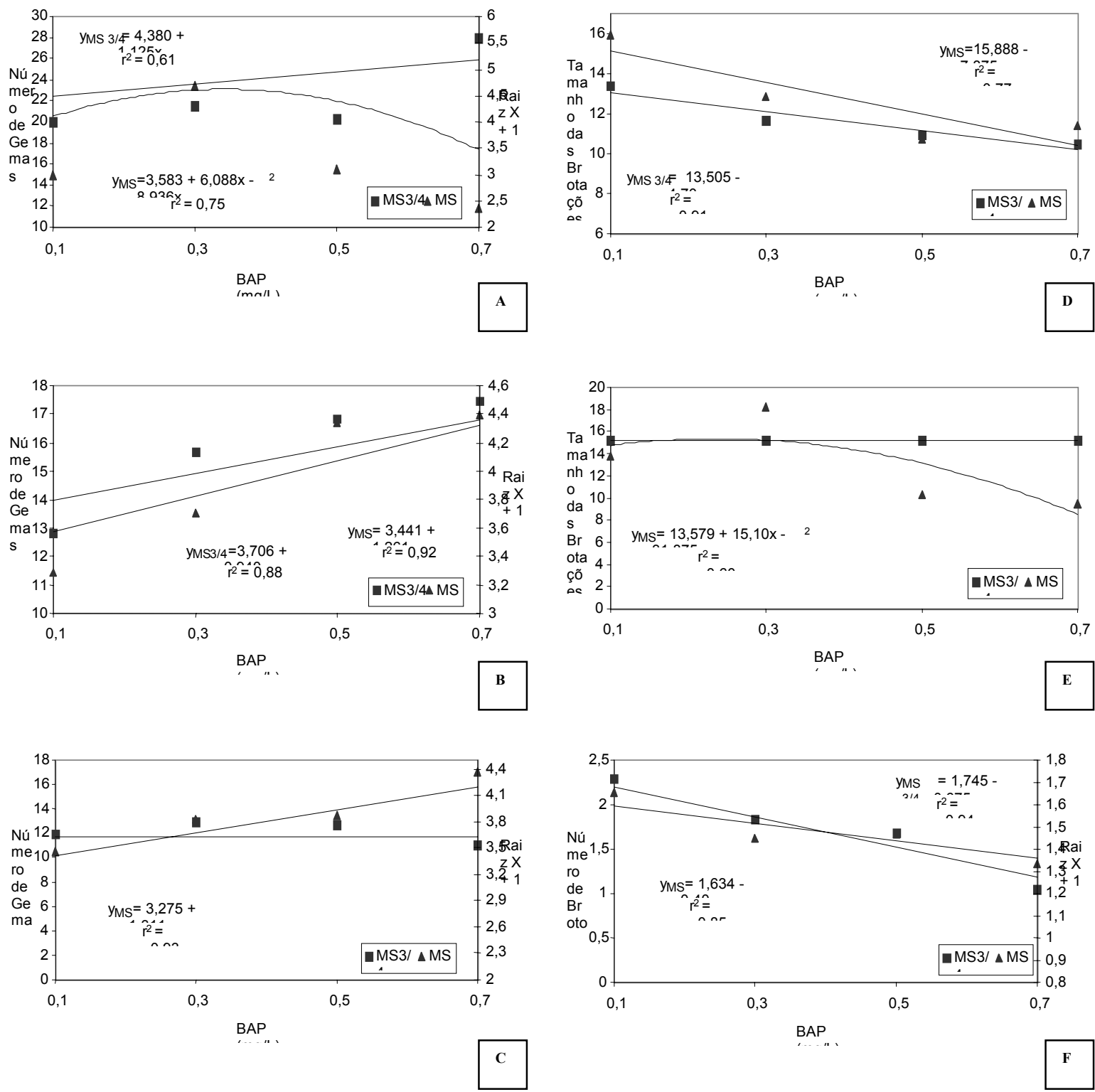

FIGURA 1A A 1F - Regressão polinomial para as variáveis número de gemas e de brotações e tamanho das brotação de porta-enxertos de Prunus em função das concentrações de BAP. FAEM/UFPEL - Embrapa Clima Temperado, Pelotas-RS, 1999.

\section{REFERÊNCIAS BIBLIOGRÁFICAS}

BOXUS, P. The production of strawberry plants by in vitro micropropagation. Journal of Horticultural Science, Ashford, v.49, p.209-210, 1986.

BOXUS, P.; QUOIRIN, M. La culture de méristèmes apicaux de quelques espèces de Prunus. Bulletin de la Societé Royale de Botanique de Belgique, Bruxelles, v.107, p.91-101, 1974.

DIMASI-THERIOU, K.; ECONOMOU, A.S. Ethylene enhances shoot formation in cultures of the peach rootstock GF-677 (Prunus persica $\times$ Prunus amygdalus). Plant Cell Reports, New York, v.15, p.87-90, 1995.

GRATTAPAGLIA, D., MACHADO, M.A. Micropropagação. In: TORRES, A.C.; CALDAS, L.S.; BUSO, J.A., (Ed.) Cultura de tecidos e transformação genética de plantas, V.1, Brasília: Embrapa - Serviço de Produção de Informação/Embrapa - CNPH,
1998. p.183-260.

HARADA, H., MURAI, Y. Micropropagation of Prunus mume. Plant Cell, Tissue and Organ Culture, Dordrecht, v.8, p.265267, 1996.

MARINO, G. Primi risultati sulla moltiplicazione in vitro di quattro portinnesti, ibridi di susino e pesco, selezionati in Francia. Rivista della Ortoflorofrutticoltura Italiana, Firenze, v.66, p.369-375, 1982.

MURASHIGE, T., SKOOG, F. A revised medium for rapid growth and bioassays with tobacco tissue cultures. Physiologia Plantarum, Copenhagen, v.15, p.473-497, 1962.

PREECE, J.E. Can nutrient salts partially substitute for plant growth regulators? Plant, Tissue Culture and Biotechnology, Rehovot, v.1, n.1, p.26-37, 1995. 
QUOIRIN, M.; LEPOIVRE, P. Étude de milieux adaptés aux cultures in vitro de Prunus. Acta Horticulturae, The Hague, v.78, p.437-442, 1977.

TABACHNICK, L.; KESTER, D.E. Shoot culture of almond peach hybrid clones in vitro. HortScience, Alexandria, v.12, n.6, p.545$547,1977$.

ZIMMERMAN, R.H. Cultivo de tejidos. In: MOORE, J.N.,
JANICK, J. Métodos genotécnicos en frutales. Mexico: AGT, 1988. p.167-182.

ZONTA, E.P.; MACHADO, A.A. SANEST - Sistema de Análise Estatística para Microcomputadores. Pelotas:UFPel, 1984. 75p.

ZUCCHERELLI, G. Moltiplicazione in vitro dei portainnesti clonali del pesco. Rivista della Ortoflorofrutticoltura Italiana, Firenze, v.41, n.2, p.15-20, 1979. 